1. Oetting WS, King RA. Molecular basis of albinism: mutations and polymorphisms of pigmentation genes associated with albinism. Hum Mutat. 1999; 13(2):99-115.

2. Lee ST, Nicholls RD, Bundey S, Laxova R, Musarella M, Spritz RA. Mutations of the P gene in oculocutaneous albinism, ocular albinism, and Prader-Willi syndrome plus albinism. N EnglJ Med. 1994;330(8):529-534.

3. Manga P, Kromberg JG, Box NF, Sturm RA, Jenkins T, Ramsay M. Rufous oculocutaneous albinism in southern African Blacks is caused by mutations in the TYRP1 gene. Am J Hum Genet. 1997; 61(5):1095-1101.

4. Newton JM, et al. Mutations in the human orthologue of the mouse underwhite gene (uw) underlie a new form of oculocutaneous albinism, OCA4. Am J Hum Genet. 2001;69(5):981-988.

5. Durham-Pierre D, King RA, Naber JM, Laken S, Brilliant $\mathrm{MH}$. Estimation of carrier frequency of a $2.7 \mathrm{~kb}$ deletion allele of the $\mathrm{P}$ gene associated with OCA2 in African-Americans. Hum Mutat. 1996; 7(4):370-373.

6. Woolf CM, Dukepoo FC. Hopi indians, inbreeding, and albinism. Science. 1969;164(3875):30-37.

7. Inagaki $\mathrm{K}$, et al. Oculocutaneous albinism type 4 is one of the most common types of albinism in Japan. Am J Hum Genet. 2004;74(3):466-471.
8. Rachel RA, et al. Spatiotemporal features of early neuronogenesis differ in wild-type and albino mouse retina. J Neurosci. 2002;22(11):4249-4263.

9. Ezeilo BN. Psychological aspects of albinism: an exploratory study with Nigerian (Igbo) albino subjects. Soc Sci Med. 1989;29(9):1129-1131.

10. Wang N, Hebert DN. Tyrosinase maturation through the mammalian secretory pathway: bringing color to life. Pigment Cell Res. 2006;19(1):3-18.

11. Halaban R, Svedine S, Cheng E, Smicun Y, Aron R, Hebert DN. Endoplasmic reticulum retention is a common defect associated with tyrosinase-negative albinism. Proc Natl Acad Sci U S A. 2000;97(11):5889-5894.

12. Chen K, Manga P, Orlow SJ. Pink-eyed dilution protein controls the processing of tyrosinase. Mol Biol Cell. 2002;13(6):1953-1964.

13. Toyofuku K, Wada I, Valencia JC, Kushimoto T, Ferrans VJ, Hearing VJ. Oculocutaneous albinism types 1 and 3 are ER retention diseases: mutation of tyrosinase or Tyrp1 can affect the processing of both mutant and wild-type proteins. FASEB J. 2001;15(12):2149-2161

14. Costin GE, Valencia JC, Vieira WD, Lamoreux ML, Hearing VJ. Tyrosinase processing and intracellular trafficking is disrupted in mouse primary melanocytes carrying the underwhite (uw) mutation. A model for oculocutaneous albinism (OCA) type 4.
J Cell Sci. 2003;116(pt 15):3203-3212.

15. Manga P, Bis S, Knoll K, Perez B, Orlow SJ. The unfolded protein response in melanocytes: activation in response to chemical stressors of the endoplasmic reticulum and tyrosinase misfolding. Pigment Cell Melanoma Res. 2010;23(5):627-634.

16. Staleva L, Manga P, Orlow SJ. The pink-eyed dilution protein modulates arsenic sensitivity and intracellular glutathione metabolism. Mol Biol Cell. 2002;13(12):4206-4220.

17. Manga P, Sato K, Ye L, Beermann F, Lamoreux ML, Orlow SJ. Mutational analysis of the modulation of tyrosinase by tyrosinase- related proteins 1 and 2 in vitro. Pigment Cell Res. 2000;13(5):364-374.

18. Manga P, Orlow SJ. Inverse correlation between pink-eyed dilution protein expression and induction of melanogenesis by bafilomycin A1. Pigment Cell Res. 2001;14(5):362-367.

19. Onojafe IF, et al. Nitisinone improves eye and skin pigmentation defects in a mouse model of oculocutaneous albinism. J Clin Invest. 2011; 121(10):3914-3923.

20. Manga P, Boissy RE, Pifko-Hirst S, Zhou BK, Orlow SJ. Mislocalization of melanosomal proteins in melanocytes from mice with oculocutaneous albinism type 2. Exp Eye Res. 2001;72(6):695-710.

21. Scott CR. The genetic tyrosinemias. Am JMed Genet C Semin Med Genet. 2006;142C(2):121-126.

\title{
Viruses and human brain tumors: cytomegalovirus enters the fray
}

\author{
Cynthia Hawkins $^{1}$ and Sidney Croul ${ }^{2}$
}

\author{
${ }^{1}$ Division of Pathology, The Hospital for Sick Children, and 2Division of Pathology, University Health Network, Toronto, Ontario, Canada.
}

\begin{abstract}
Medulloblastoma is the most common malignant brain tumor in children. Overall survival rates have improved in recent years as a result of risk-stratified treatment regimens. However, medulloblastoma remains associated with substantial mortality, and survivors often experience debilitating neurological, endocrinological, and social sequelae as a result of treatment. Targeted and less toxic therapeutic strategies are therefore needed. In this issue of the JCI, Baryawno et al. report their findings that a large percentage of primary medulloblastomas and medulloblastoma cell lines are infected with human cytomegalovirus (HCMV) and suggest that targeting this virus could provide a new way to treat individuals with medulloblastoma.
\end{abstract}

Brain tumors account for $20 \%$ of all neoplasms in children and are the largest group of solid tumors that develop in childhood (1). Medulloblastoma is the most common malignant pediatric brain tumor, constituting $20 \%-25 \%$ of pediatric central nervous system neoplasms $(2,3)$. Its incidence is estimated at 2-6 cases per million children per year, with approximately 540 new cases diagnosed annually in the United States $(2,4)$. Medulloblastoma typ-

Conflict of interest: The authors have declared that no conflict of interest exists.

Citation for this article: J Clin Invest. 2011; 121(10):3831-3833. doi:10.1172/JCI60005. ically arises in the midline cerebellum, in the region of the mid- and inferior vermis. Current treatment includes surgery, craniospinal irradiation, and chemotherapy. Overall survival for all medulloblastoma patients is roughly $50 \%-60 \%$ in population-based studies (5). However, as we have gained a better understanding of clinical risk factors, the incorporation of patient stratification in larger, multi-institutional studies has resulted in improved survival. Currently, there are three major treatment strategies for medulloblastoma patients based on their clinical status. For patients younger than 3-5 years, treatments are aimed at maximizing survival while avoid- ing radiation $(6,7)$. Older patients are stratified by the extent of resection and metastatic status. Patients with metastatic disease or a less-than-optimal resection are classified as high-risk and are treated with high doses of craniospinal irradiation (36-39 Gy) and aggressive chemotherapy. Patients with totally, or near-totally, resected, non-disseminated disease are designated average-risk. This is the most prevalent group, and these patients are treated with a combination of lower-dose irradiation and chemotherapy. This clinical stratification has resulted in higher cure rates for all groups, with $80 \%$ of average-risk patients reaching progression-free survival at 5 years $(8,9)$. Despite the improved survival, there still remains a substantial amount of mortality associated with medulloblastoma, and survivors often experience neurological, endocrinological, and social sequelae as a result of treatment. Thus, many researchers are seeking to develop new, more targeted and less toxic therapeutic strategies. In this issue of the JCI, Baryawno et al. describe a potential novel therapeutic strategy for medulloblastoma 

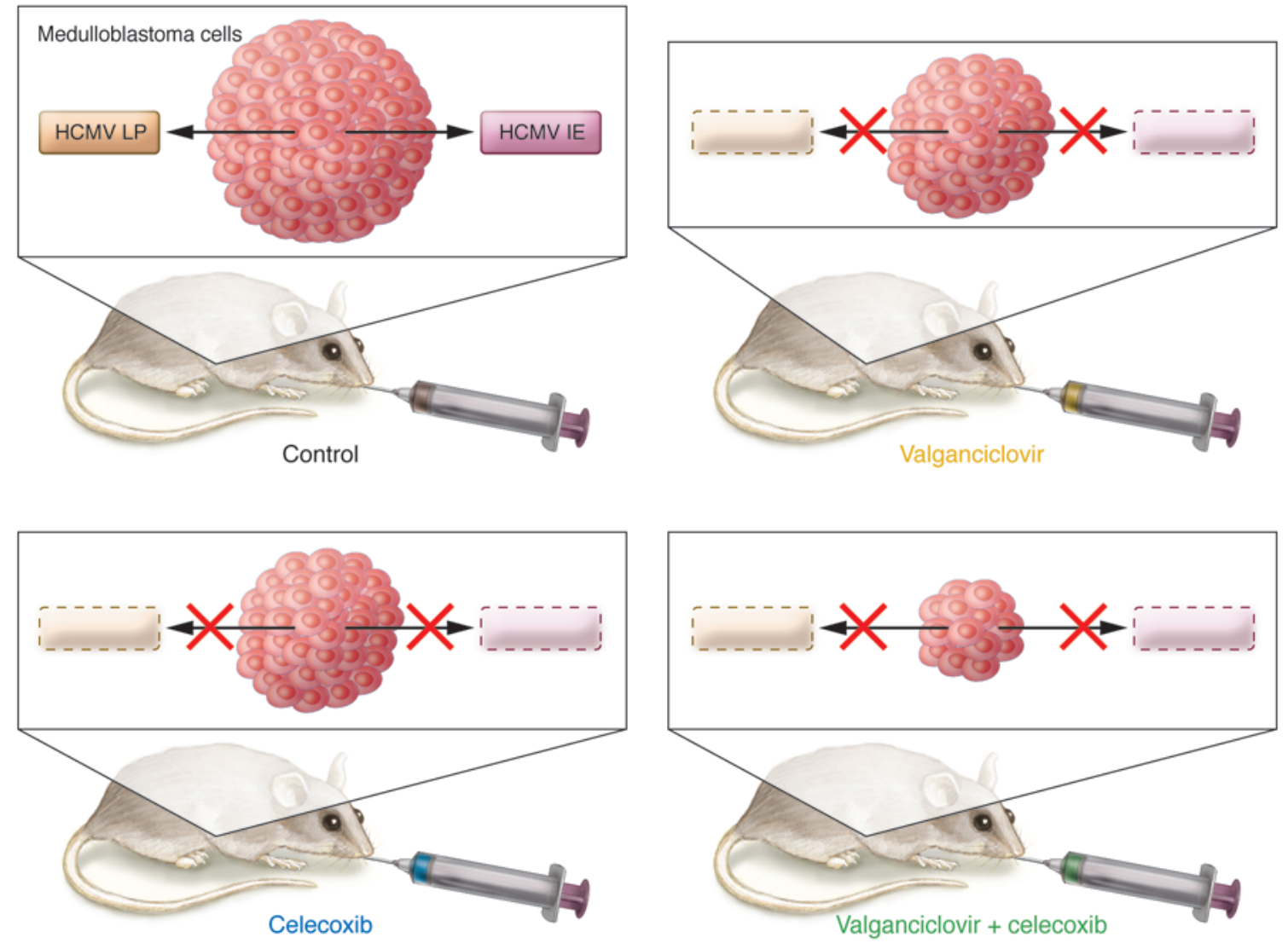

Figure 1

Effect of valganciclovir and celecoxib on medulloblastoma cell lines expressing HCMV proteins as observed by Baryawno and colleagues (10). Injection of medulloblastoma cell lines expressing HCMV proteins into the flanks of nude mice results in tumors (Control), which are reduced in size following treatment with either valganciclovir, which targets the DNA polymerase during HCMV replication, or the COX-2 inhibitor celecoxib, which prevents $\mathrm{HCMV}$ replication by decreasing $\mathrm{PGE}_{2}$ levels. Treatment with a combination of celecoxib and valganciclovir causes a greater reduction in tumor size than either drug alone. LP, HCMV late protein; IE, HCMV immediate early protein.

that takes advantage of their finding that human cytomegalovirus (HCMV) is frequently expressed in such tumors (10).

\section{Can viruses cause brain tumors?}

Whether viruses have a causal role in brain tumor development has been hotly debated for decades (11). Epidemiologic data pointing to a potential role for viruses in the development of brain tumors include several studies reporting an increased risk of developing a childhood brain tumor in individuals whose mothers were infected with various viruses, such as those that cause chicken pox, mumps, and rubella, during pregnancy $(12,13)$. However, the largest area of inquiry into the possibility of an infectious etiology of brain tumors comes from studies of polyomaviruses, a genus of viruses that includes simian vacuolating virus 40 (SV40). In vitro, the $\mathrm{T}$ antigen encoded by many polyomaviruses readily transforms cells and induces CNS tumors, including medulloblastomas, gliomas, and choroid plexus papillomas, in a variety of animal models (14). Human studies correlating viruses and brain tumors include epidemiological studies suggesting that polyoma virus-contaminated vaccinations administered to women in the 1950s and '60s were associated with increased risk of brain tumors in their children (15-17), and more recently, those indicating the presence of polyoma DNA and protein in human brain tumors, including the detection of polyoma JC virus in medulloblastoma (18). Despite the spate of early experiments indicating a potential role for polyomaviruses in brain tumor formation, over time it has been difficult, some would say near impossible, to move from correlation to cause in the arena of human brain tumors. Over the years, the literature has been peppered with claims and counterclaims of polyomavirus detection in human tumor specimens $(18,19)$, but definitive proof of polyomaviruses causing brain tumors is still not available.

\section{Can viruses be used to treat brain tumors?}

The controversy surrounding the potential causal role of viruses in brain tumor development has been swirling for years. More recently, however, interest in viral CNS tumor pathogenesis has yielded to the related field of viral therapy for brain tumors (20). Oncolytic viral therapy uses replicationcompetent viruses to selectively infect and kill cancer cells while leaving normal, nontransformed cells intact. Viruses used in this way in clinical trials for malignant glial brain tumors include herpes simplex viruses, adenoviruses, reoviruses, and Newcastle disease viruses (20). Although in trial for malignant gliomas, this strategy has not yet been evaluated for the treatment of medulloblastoma. However, preclinical data exist suggesting that measles virus might be an effective oncolytic virus in individuals with medulloblastoma (21). Studebaker et al. demonstrated that the measles virus receptor CD46 
was expressed in 13 of 13 medulloblastoma samples tested and that exposure to measles virus led to substantial cell death in medulloblastoma cell lines and xenografts (21). Similar preclinical data suggest that oncolytic viral therapy using myxoma virus (22) and picornavirus (23) could also be effective for the treatment of medulloblastoma. However, thus far, clinical trials evaluating the potential efficacy of oncolytic viral strategies for the treatment of brain tumors have revealed several barriers, including the host antiviral immune response (which is emerging as an issue for virus-based therapies in general); the need to develop ways to minimize neurotropism and thereby neurotoxicity while maintaining oncolytic efficacy; and the need to optimize viral delivery to the tumor (20).

\section{Can the presence of virus be used to target brain tumors therapeutically?}

HCMV DNA and proteins have been found in tumors of different origins, including $90 \%-100 \%$ of high-grade glial brain tumors (24). Unlike polyomaviruses, CMV is not considered to be oncogenic itself and has likewise not been used as an oncolytic virus. In this issue of the JCI, Baryawno et al. report their work examining the prevalence of HCMV in medulloblastomas and whether the presence of the virus can be used to target medulloblastoma therapeutically (10). Of the 37 primary medulloblastomas examined by Baryawno et al. for the presence of HCMV, 92\% expressed HCMV immediate early proteins and $73 \%$ expressed late proteins. Similarly, HCMV proteins were detected in all 8 medulloblastoma cell lines tested, including within the CD133+ putative tumor-initiating cell population.

Baryawno and colleagues then went on to test whether either ganciclovir, which targets the DNA polymerase during HCMV replication, or the COX-2 inhibitor celecoxib, which prevents HCMV replication by decreasing $\mathrm{PGE}_{2}$ levels, affected medulloblastoma growth (10). They found that ganciclovir decreased the clonogenic capacity of HCMVpositive cell lines but had no effect on HCMVnegative lines. This effect was augmented by the addition of celecoxib. While this study did not address these questions, it will be important to test what effect the drugs have on cell growth in vitro, and whether the effects are cytotoxic or cytostatic.

In a flank xenograft model, Baryawno et al. found that medulloblastoma tumor volume could be reduced by approximately $40 \%$ in mice treated with either valganciclovir or celecoxib alone, and by $72 \%$ with a combined drug regimen (10). Similar to the in vitro data, HCMV-negative xenografts were not affected by the drug treatment, supporting the hypothesis that the effect was specific to HCMV-positive tumor cells. Future preclinical studies looking at whether this drug treatment can extend the survival of mice in an orthotopic xenograft model and whether these drugs can be effectively combined with other chemotherapeutic agents and/or radiotherapy will be key.

The data presented by Baryawno et al. demonstrating in vivo reduction of tumor size following treatment with valganciclovir and celecoxib (ref. 10 and Figure 1) are intriguing, as they raise a new potential route through which viruses may be exploited to treat brain tumors. The relatively low toxicity and good blood brain barrier penetration of these agents make them attractive for clinical use, eliminating many of the barriers that still face oncolytic viral therapies. However, the claim of Baryawno and colleagues that their observations suggest a pathogenic role for HCMV in medulloblastoma (10) is less well substantiated. As for polyomavirus, a causal role for HCMV in medulloblastoma development has yet to be shown.

\section{Conclusion}

Whether viruses are a major cause of brain tumors may never be conclusively determined. However, as shown by Baryawno et al. (10), we may be able to exploit our knowledge of the presence of viruses and viral antigens in brain tumors to develop novel therapies for these devastating diseases.

\section{Acknowledgments}

Cynthia Hawkins is funded by grants from the Canadian Institutes for Health Research (MOP115004) and the National Brain Tumor Society.

Address correspondence to: Cynthia Hawkins, Department of Paediatric Laboratory Medicine, The Hospital for Sick Children, 555 University Avenue, Toronto, Ontario M5G 1X8, Canada. Phone: 416.813.5938; Fax: 416.813.5974; E-mail: cynthia.hawkins@sickkids.ca.

1. Stiller CA. Population based survival rates for childhood cancer in Britain, 1980-1991. BMJ. 1994; 309(6969):1612-1616.

2. McNeil DE, Cote TR, Clegg L, Rorke LB. Incidence and trends in pediatric malignancies medulloblastoma/primitive neuroectodermal tumor: a SEER update. Surveillance epidemiology and end results. Med Pediatr Oncol. 2002;39(3):190-194.

3. Park TS, Hoffman HJ, Hendrick EB, Humphreys RP, Becker LE. Medulloblastoma: clinical presentation and management. Experience at the Hospital for Sick Children, Toronto, 1950-1980. J Neurosurg. 1983;58(4):543-552.

4. Roberts RO, Lynch CF, Jones MP, Hart MN. Medulloblastoma: a population-based study of 532 cases. J Neuropathol Exp Neurol. 1991;50(2):134-144.

5 . Korones DN. Treatment of newly diagnosed diffuse brain stem gliomas in children: in search of the holy grail. Expert Rev Anticancer Ther. 2007;7(5):663-674.

6. Grill J, et al. Treatment of medulloblastoma with postoperative chemotherapy alone: an SFOP prospective trial in young children. Lancet Oncol. 2005;6(8):573-580.

7. Rutkowski S, et al. Treatment of early childhood medulloblastoma by postoperative chemotherapy alone. N Engl J Med. 2005;352(10):978-986

8. Gajjar A, et al. Risk-adapted craniospinal radiotherapy followed by high-dose chemotherapy and stem-cell rescue in children with newly diagnosed medulloblastoma (St Jude Medulloblastoma-96): long-term results from a prospective, multicentre trial. Lancet Oncol. 2006;7(10):813-820.

9. Packer RJ, et al. Phase III study of craniospinal radiation therapy followed by adjuvant chemotherapy for newly diagnosed average-risk medulloblastoma. J Clin Oncol. 2006;24(25):4202-4208.

10. Baryawno N, et al. Detection of human cytomegalovirus in medulloblastomas reveals a potential therapeutic target. J Clin Invest. 2011; 121(10):4043-4055.

11. Maginnis MS, Atwood WJ. JC virus: an oncogenic virus in animals and humans? Semin Cancer Biol. 2009;19(4):261-269.

12. Adelstein AM, Donovan JW. Malignant disease in children whose mothers had chickenpox, mumps, or rubella in pregnancy. Br Med J. 1972;4(5841):629-631.

13. Linet MS, et al. Maternal and perinatal risk factors for childhood brain tumors (Sweden). Cancer Causes Control. 1996;7(4):437-448.

14. Croul S, Otte J, Khalili K. Brain tumors and polyomaviruses. J Neurovirol. 2003;9(2):173-182.

15. Farwell JR, Dohrmann GJ, Flannery JT. Medulloblastoma in childhood: an epidemiological study. J Neurosurg. 1984;61(4):657-664.

16. Fraumeni JF Jr, Stark CR, Gold E, Lepow ML. Simian virus 40 in polio vaccine: follow-up of newborn recipients. Science. 1970;167(914):59-60.

17. Heinonen OP, Shapiro S, Monson RR, Hartz SC, Rosenberg L, Slone D. Immunization during pregnancy against poliomyelitis and influenza in relation to childhood malignancy. Int J Epidemiol. 1973;2(3):229-235

18. Khalili K, Krynska B, Del Valle L, Katsetos CD, Croul S. Medulloblastomas and the human neurotropic polyomavirus JC virus. Lancet. 1999; 353(9159):1152-1153.

19. Rollison DE, et al. Investigation of human brain tumors for the presence of polyomavirus genome sequences by two independent laboratories. Int $J$ Cancer. 2005;113(5):769-774.

20. Zemp FJ, Corredor JC, Lun X, Muruve DA, Forsyth PA. Oncolytic viruses as experimental treatments for malignant gliomas: using a scourge to treat a devil. Cytokine Growth Factor Rev. 2010;21(2-3):103-117.

21. Studebaker AW, Kreofsky CR, Pierson CR, Russell SJ, Galanis E, Raffel C. Treatment of medulloblastoma with a modified measles virus. Neuro Oncol. 2010;12(10):1034-1042.

22. Lun XQ, et al. Targeting human medulloblastoma: oncolytic virotherapy with myxoma virus is enhanced by rapamycin. Cancer Res. 2007; 67(18):8818-8827.

23. Yu L, et al. A single intravenous injection of oncolytic picornavirus SVV-001 eliminates medulloblastomas in primary tumor-based orthotopic xenograft mouse models. Neuro Oncol. 2011;13(1):14-27.

24. Cobbs CS, et al. Human cytomegalovirus infection and expression in human malignant glioma. Cancer Res. 2002;62(12):3347-3350. 